\title{
EL RETO DE LA MUESTRA BIOLÓGICA EN LOS ESTUDIOS FARMACOGENÉTICOS
}

\begin{abstract}
Alexandre Bota i Arqué*
Resumen: Este trabajo parte de la constatación del importante incremento de estudios farmacológicos que lleva asociado un estudio farmacogenético sin que exista un conocimiento muy claro de sus consecuencias. Su primer reto es dilucidar si estos estudios tienen mayores implicaciones que las determinaciones de parámetros de rutina. No se puede obviar que la genética genera cierta preocupación debido, entre otros factores, al lenguaje técnico, la desinformación, las simplificaciones que generan los medios de comunicación, y su complejidad. El segundo objetivo es definir qué figura de propiedad tienen los investigadores o las empresas patrocinantes de las muestras biológicas y los datos genéticos en los estudios de farmacogenética.
\end{abstract}

Palabras clave: Muestra biológica, farmacogenética, bioética

\section{BIOLOGICAL SAMPLE'S CHALLENGE ON PHARMACOGENETIC STUDIES}

\begin{abstract}
This work starts stating the great increase of pharmacological studies associated with pharmacogenetic studies without clear knowledge of their consequences. The first challenge is to find out whether pharmacogenetic studies have greater implications than the determination of routine parameters. We cannot obviate that genetics engenders special worries due to several factors, such as: technical language, lack of information, media simplifications and complexity. The second goal is to define which property rights researchers or sponsor companies have on biological samples and genetic data in pharmacogenetic studies.
\end{abstract}

Key words: Biological sample, pharmacogenetics, bioethics

\section{O OBJETIVO DA MOSTRA BIOLÓGICA NOS ESTUDOS FARMACOGENÉTICOS}

Resumo: Este trabalho parte da constatação do importante incremento dos estudos farmacológicos que leva associado um estudo farmacogenético sem que exista um conhecimento muito claro de suas conseqüências. Seu primeiro objetivo é esclarecer se estes estudos tem maiores implicações que as determinações de parâmetros de rotina. Não se pode considerar obvio que a genética gera certa preocupação devido, entre outros fatores, à linguagem técnica, à desinformação, às simplificações geradas pelos meios de comunicação, e sua complexidade. O segundo objetivo é definir que figura de propriedade tem os pesquisadores ou as empresas patrocinadoras das amostras biológicas e os dados genéticos nos estudos de farmacogenética.

Palavras-chave: Amostra biológica, farmacogenética, bioética

* Institut de Tecnoética de Barcelona

Correspondencia: abota@servet.uab.es 


\section{El reto de la muestra biológica en los estudios farmacogenéticos}

La genética ha abierto un mundo de posibilidades individuales y colectivas. La información genética de los sujetos trasciende su individualidad para afectar a la familia y a la sociedad. Pero estas posibilidades no pueden ser analizadas en un contexto hipotético, sino en la perspectiva del sistema económico de libre mercado y en el momento presente, cuando la generación de conocimiento está altamente protegida. En este nuevo contexto, las muestras biológicas y la información genética, conjuntamente con el historial clínico, son un elemento de comercio o de acuerdos entre industria y sistema público de salud (como en los casos de Islandia y Estonia) con el objetivo de desarrollar la farmacogenética ${ }^{1}$. Sin embargo, el desarrollo de una posible nueva medicina, tan unido a las corporaciones farmacéutico-sanitarias que utilizan la protección del conocimiento y las patentes para rentabilizar las inversiones, dibuja un horizonte confuso, de difícil análisis y de consecuencias sociales importantes. Con el objetivo de clarificar y entender la necesidad de investigar con muestras biológicas y prever hacia adónde se proyecta la farmacogenética, es necesario hacer algo de historia sobre el origen de la investigación farmacológica.

\section{La terapéutica moderna (Siglo XX)}

La investigación y el desarrollo de compuestos químicos para el tratamiento de enfermedades no progresaron hasta que la farmacología se situó en la terapéutica moderna, bajo la máxima de hallar una sustancia de acción específica contra el agente nocivo. El primer compuesto químico de esta era fue el Salvaran², antimi-

Biobancos. Trames Journal of the Humanities and Social Sciences. No 1/2, Vol. 8, 2004.

2 La utilización de sales de mercurio para el tratamiento de la sífilis durante el siglo XIV fue un antecedente digno de olvidar por sus efectos más tóxicos que curativos. crobiano que poseía la especificidad de una baja toxicidad para las células humanas. Sin embargo, el desarrollo de nuevos compuestos químicos, así como el descubrimiento de compuestos naturales, como los antibióticos, situaron a la farmacología en la necesidad de comprobar que los compuestos hallados o sintetizados en el laboratorio producían un tratamiento eficaz. La terapéutica moderna funcionaba bajo dos axiomas: a) las dianas de los compuestos eran, principalmente, elementos exógenos al propio organismo y b) la humanidad conformaba un conjunto poblacional más o menos homogéneo, de lo cual se podía concluir que si un tratamiento funcionaba su eficacia era extrapolable a toda la humanidad.

No obstante, la experiencia clínica ha demostrado largamente que la extrapolación no es correcta. Es habitual constatar que no todos los pacientes responden de igual forma a los tratamientos. Esto se debe, principalmente, a dos tipos de factores: endógenos, como la dotación genética, y exógenos, como la alimentación y los hábitos, entre otros ${ }^{3}$. Según un estudio del Reino Unido, una de cada quince admisiones hospitalarias se debe a efectos adversos de algunos medicamentos (1). Otro estudio estima que en los EEUU cada año mueren 106.000 pacientes y que 2,2 millones resultan dañados a causa de los efectos adversos de fármacos prescritos(2). Estas estimaciones comprueban los riesgos inherentes de los fármacos y ponen en tela de juicio la teórica inocuidad o la toxicidad controlada de los fármacos. Pero no son únicamente los factores genéticos los que afectan a su toxicidad, también puede deberse a una incorrecta prescripción, a la mala adherencia o a la interacción con otras sustancias u otros medicamentos, por ejemplo.

\footnotetext{
Rodríguez-Villanueva J. Integración de la genética en la investigación clínica: farmacogenética y genómica funcional. ICB Digital 2002; 3. [Sitio en Internet] Disponible en www.icf.uab.es/icbdigital/pdf/articulo/articulo3.pdf
} 
Simplificando, se puede afirmar que, en la terapéutica moderna, la causa de la enfermedad estaba fuera del cuerpo y los fármacos se diseñaban para combatir ese organismo exógeno. Pero, en la actualidad, se sabe que algunas mutaciones genéticas ${ }^{4}$ pueden causar o predisponer a ciertas enfermedades o modificar la eficiencia o toxicidad de ciertos fármacos. En este nuevo paradigma la enfermedad se encuentra también en nuestros genes, y la medicina ha de diseñar una nueva estrategia para darle respuesta.

\section{La farmacogenética}

Llamaremos así a la disciplina que estudia la influencia de los factores genéticos en la acción de los medicamentos(3), lo que realiza mediante la identificación de genes específicos y productos génicos asociados a enfermedades -los cuales podrían actuar como señales para nuevas drogas(4) - y de los perfiles/esquemas genéticos asociados a los efectos secundarios de las medicinas. En esta última modalidad, analiza si la población en estudio, que ha sufrido efectos secundarios, posee alguna particularidad genética que permita identificar qué efectos secundarios o adversos se producen.

Los estudios de farmacogenética han hallado algunas alteraciones genéticas relevantes para la efectividad de algunos fármacos, como las mutaciones del gen que codifica para el citocromo P450 CYP2D6, proteína responsable del metabolismo de numerosos fármacos: clozapina, desipramina, fluvoxamina, imipramina, olanzapina, amiodarona, oxprenolol, entre muchos otros. Una mutación del gen puede alterar la capacidad metabólica de la proteína con lo cual se altera la disponibilidad del fármaco en sangre. Puede darse el caso de que la

Los genes en sí no causan ni predisponen, sino que la ausencia o alteración de los productos de su transcripción son los que causan las diferentes patologías. proteína metabolice muy rápidamente o muy lentamente, lo cual provocará que el nivel de la droga en la sangre no sea el óptimo para realizar la función estudiada. Existe una relación evidente, no la única, entre la efectividad y seguridad de los fármacos y la dotación genética.

La farmacogenética pretende diseñar una nueva farmacología donde el tipo de fármaco y la dosis dependan de la dotación genética del paciente; también pretende hallar nuevas dianas terapéuticas para diseñar fármacos más específicos. Sin embargo, a pesar de los -teóricamente- extraordinarios beneficios, existen riesgos. Para determinarlos sería necesario prever cuál será la penetración de la farmacogenética en nuestras sociedades, tarea imposible ya que en su desarrollo intervienen múltiples intereses muchas veces contrapuestos: la protección intelectual de la información genética y del material genético como patrimonio de la humanidad, la necesidad de invertir grandes cantidades de dinero - que deben ser recuperables-y la teórica universalización del acceso a la salud que puede provocar problemas de inequidad y de justicia distributiva. Pero no intentaré cuestionar la eticidad de los estudios farmacogenéticos, sino interrogar, únicamente, sobre la posesión de la muestra biológica y de la información genética de los participantes en las investigaciones farmacogenéticas.

\section{El ser humano}

En las sociedades occidentales secularizadas el cuerpo físico es el elemento que da existencia al individuo que se constituye en fundamento de la sociedad. Entendiéndose el cuerpo como esa realidad que trasciende su función biológica, siendo, a la vez, realidad biológica y simbólica. El cuerpo es fundamento y, como tal, no puede ser entendido como una cosa o un bien, no se puede realizar transacciones con él, el cuerpo está excluido como objeto de dere- 
cho(5). La sociedad sin cuerpos individuales no existe y no se puede instaurar, por esto los marcos jurídicos occidentales reconocen al cuerpo vivo como la persona, y se respetan todas las expresiones de este cuerpo, ya sean físicas, intelectuales, estéticas (derecho a la integridad física, la no esclavitud, derecho a la libertad de expresión y artística) ${ }^{5}$. En occidente, el cuerpo es uno de los anclajes que la sociedad necesita para fijar su identidad(6), pero no es únicamente el reconocimiento del cuerpo propio, sino del cuerpo del otro como igual al propio lo que genera un gran avance en la interrelación social, la extensión del reconocimiento del otro como igual es la base del sistema. Todos los seres humanos nacen libres e iguales en dignidad y derechos, y dotados como están de razón y conciencia deben comportarse fraternalmente los unos con los otros ${ }^{5}$.

\section{El material genético humano}

El material genético humano está formado por 22 pares de cromosomas autosómicos y un par de cromosomas sexuales, la procedencia de los cuales es $50 \%$ de cada progenitor. Además, existe un cierto material genético que se halla en las mitocondrias, de procedencia femenina. En cada cromosoma hay un número determinado de genes que configuran el genotipo de los individuos; por esto, todas las células del organismo poseen la misma dotación genética, aun cuando expresen proteínas diferentes. Es importante comprender que las células de la retina son iguales genéticamente a las de la epidermis que se eliminan diariamente. Se puede afirmar que el material genético es común en todas las células no sexuales de los individuos y que esta información irá siendo transcrita en consonancia con los estímulos externos desde el momento de la fecundación hasta la muerte.

ONU. Declaración Universal de los Derechos Humanos. [Sitio en Internet] Disponible en http://www.un.org/spanish/ aboutun/hrights.htm

\section{La muestra biológica}

Esta muestra es una fracción estadísticamente significativa que aporta información sobre un todo inaccesible, con el fin de conocer diferentes elementos. Una biopsia realizada durante una investigación pretende extraer muestras de tejidos y líquidos, entre otras sustancias, con el objetivo de inferir y diagnosticar qué le está sucediendo al órgano o al tejido en su conjunto. Una muestra biológica destinada a investigación genética pretende obtener material genético del individuo. La muestra biológica es la base que utiliza el conocimiento científico-médico para hacer la inferencia inductiva hacia el todo, lo cual pone de relieve que la muestra (como parte y como todo) y el organismo tienen un vínculo evidente.

La muestra biológica permite inferir acerca del órgano o tejido que se está estudiando, pero también permite inferir sobre el organismo completo, ya que el material genético es común en todas las células; incluso permitiría inferir sobre grupos genéticos y grupos étnicos. El gran problema es saber, o decidir, si la muestra biológica, separada del cuerpo, forma parte del cuerpo, si es objeto de derechos fundamentales, si es un bien que necesita protección jurídica especial o puede entrar en la órbita del mercado sin ninguna precaución(7).

La muestra biológica, separada del paciente en el transcurso de un proceso investigativo, pareciera ser, biológicamente, una parte diferenciada del sujeto mismo. Pero la realidad del cuerpo trasciende la biologicidad, como se constata en la declaración europea sobre investigación biomédica. Este convenio protege al ser humano en su dignidad y su identidad, y garantiza a toda persona, sin discriminación alguna, el respeto a su integridad y a sus demás derechos y libertades fundamentales en relación con las aplicaciones de la biología y la medicina(8). 
El problema de esta sentencia es definir la dignidad humana y la integridad. La integridad del sujeto será diferente dependiendo de la perspectiva, y la dignidad puede verse afectada por acciones realizadas, a posteriori, sobre algo separado del cuerpo humano, como una muestra biológica. Lo que lleva a concluir que la muestra humana separada del cuerpo, aunque no sea una parte física indispensable y su extracción no atente a la integridad del cuerpo (como podría ser una muestra de sangre), sigue formando parte del cuerpo. Pudiéndose entonces afirmar que la muestra biológica, sea un tejido o fluido, se regenere o no, mantiene un vínculo con el cuerpo, primeramente por la existencia de un material genético que hace casi imposible la anonimización y, segundo, porque las consecuencias de la investigación pueden afectar la dignidad del individuo, que no es física. La muestra está vinculada al sujeto, aunque sea anónima y en poder del investigador, y aun siendo imposible su trazabilidad por motivos técnicos.

Considero que no existe justificación válida para distinguir la muestra obtenida en un proceso diagnóstico, terapéutico o en una investigación, debido a que el problema debe ser fundamentado y no puede ser resuelto en aras del beneficio terapéutico recibido. Es necesario entender la figura de posesión en relación con las muestras biológicas que la sociedad otorga a los investigadores y empresas, debido a que el cuerpo humano y sus partes no deberán ser objeto de lucro(8).

\section{¿Por qué nace la preocupación?}

Es difícil determinar un origen temporal y causal concreto, más bien ha sido una suma de factores la que ha desencadenado una creciente preocupación en relación con las muestras biológicas, tales como la obtención ilícita, la utilización para investigaciones no autorizadas, la solicitud no respetada del retorno o destruc- ción de las muestras, la mercantilización, la venta de muestras biológicas humanas y la patentabilidad de invenciones donde la contribución de la muestra biológica fue fundamental, entre otras anomalías.

La cristalización de estos factores se ha empezado a producir con diversas denuncias que anticipan un futuro controversial respecto de las muestras biológicas y de los datos genéticos. Tres casos para ejemplificar la situación: (a) Yanomamis del Brasil solicitaron el retorno de muestras de sangre que fueron colectadas años atrás; (b) la empresa Spitter, con sede en Bruselas, después de hacer suspensión de pagos, pretendió vender un banco de muestras genéticas donadas para realizar investigaciones; (c) el famoso caso de Moore v/s Regents, en el cual el doctor que estaba tratando a un paciente descubrió que sus células producían una sustancia valiosa, tanto en el plano científico como en el comercial, y, acto seguido, la patentó en provecho de cinco beneficiarios: el médico del paciente, el hospital y el investigador, más un instituto de genética y una compañía farmacéutica.

El problema reside en que, por una parte, el ser humano no puede ser abordado como un medio, sino como un fin en sí mismo; pero, por otra, la medicina, la investigación científica y la industria necesitan poder investigar, trabajar con el cuerpo humano o con sus partes. Por esto resulta necesario ver cómo se establece, si es posible, un puente entre la existencia del cuerpo como una realidad no transable y las necesidades de la industria, la investigación y la medicina insertas en una dinámica tecnocientífica que, en la sociedad occidental, busca el lucro económico.

\section{¿Cómo establecer este vínculo en la donación?}

Un puente entre la existencia del cuerpo como una realidad no transable y la necesidad 
de algunos humanos de obtener órganos o tejidos humanos se desarrolló a través del concepto de "donación de órganos, tejidos o fluidos", concepto que, por extensión, se ha estado utilizando para las muestras biológicas en las investigaciones farmacógenéticas.

Sin embargo, existe una diferencia significativa entre los dos tipos de donaciones: la donación de órganos y tejidos responde a una necesidad de salud, sin beneficio económico directo. Se habla de vidas humanas y de calidad de vida, lo cual no tiene valoración económica. En la donación de muestras biológicas y datos genéticos para la investigación hay un interés científico y un nada desdeñable interés económico. Gran parte de la investigación biomédica es con fines lucrativos y las perspectivas son que esta tendencia, al menos en los países desarrollados, vaya en aumento. Todas las legislaciones hacen hincapié en que la donación es un acto de gratitud: no se puede percibir compensación alguna por la donación de tejidos humanos y no se puede exigir al receptor precio alguno por el tejido $\mathrm{u}$ órgano implantado. Pero, ¿qué sucede cuando el otro es un investigador o una empresa que buscan un lucro económico?

Se han dado algunas razones por las cuales la muestra biológica no puede constituirse como un bien, lo cual podría cuestionar la idoneidad de la figura de la donación. De un bien material se puede tener propiedad y en la donación se transfiere esta propiedad o dominio al aceptor. Pero con la muestra biológica, ¿qué se está transfiriendo realmente al investigador o la empresa? En la donación de órganos, al tornarse anónimo el órgano, se transfiere todo dominio y posesión al receptor; no obstante, cuando, desafortunadamente, se trata de donantes familiares éstos pueden ejercer presiones indebidas al aceptor recriminando comportamientos, no existiendo, entonces, una donación completa. Pero en la investigación farmacoge- nética el fin consiste en descubrir cierta peculiaridad genética que, de cierta forma, dé un producto patentable para que genere beneficios en salud y económicos. Sin embargo, en este caso el sujeto está, hasta el momento, imposibilitado para recibir compensaciones.

En contrapartida, cuando de la investigación con estas muestras celulares o genéticas se pudiera derivar un bien futuro si se realizase una transacción, la utilización de la muestra resultaría inválida, ya que la donación no puede comprender los bienes futuros ${ }^{6}$. El acto de donar la muestra o los datos genéticos imposibilita la patentabilidad de lo que de ella se pudiera derivar; la donación imposibilita la patentabilidad, porque sería apropiarse de un bien que el donador no conocía, puesto que sería generar un bien que no existía y, finalmente, sería situar las partes del cuerpo o la información genética en la órbita de lo económico. Si la sociedad fuera respetuosa con sus propios principios, toda nueva invención que se desease patentar para la cual fuera imprescindible la contribución de alguna muestra biológica o de los datos genéticos humanos no sería patentable.

Como hasta este momento no existe legislación sobre las muestras biológicas con fines investigativos, se puede hacer el parangón con la ficha clínica(9); a pesar de las diferencias, poseen ciertas particularidades que las hacen, temporalmente, comparables. Primero, la muestra biológica es manipulada, lo cual le confiere un valor añadido en relación con la muestra extraída; segundo, es un soporte de datos relativos a la salud del paciente; y, tercero, los sujetos no tienen la posesión física de la muestra, como sucede con la ficha clínica.

A mi entender, los investigadores o las empresas poseerían el usufructo de la muestra biológica siempre y cuando éste no alterara la in-

Código Civil Mexicano. Art. 2333. 
tención o la voluntad del sujeto cuando las dos partes instauraron la voluntad de cooperar en la investigación o en el tratamiento terapéutico. En esta situación, cuando el participante conoce, entiende y acepta los procedimientos y finalidades de la investigación, la muestra y los datos se conforman como una realidad con un valor añadido que permite el avance del conocimiento, $\mathrm{y}$ el sujeto pierde su vinculación con la muestra. Ésta podría ser una de las deficiencias de esta postura, ya que la legislación española y europea hablan de datos y no de la base de estos datos, la muestra biológica, que es el problema que nos incumbe. La legislación estipula la relación del sujeto con los datos de la ficha clínica, no la posesión de la ficha clínica, y, desde esta postura, se afirma que el donante tiene derecho a acceder al resultado de las pruebas, y hasta tendría derecho a exigir nuevas pruebas para dar veracidad a los datos almacenados, pero no habla de la propiedad de la muestra. Esto es consecuencia de que, al ser manipulada por el investigador, consideran que ésta ya no es propiedad del donante, sino del centro o del investigador, postura que considero errónea en su fundamento. Entiendo que la muestra mantiene un vínculo con el donante que no desaparece por muchas transformaciones que realice el investigador; mientras posea elementos que hagan posible su seguimiento, se ha de tener presente que la muestra ha sido donada para fines investigativos. El paciente no recibe ni puede recibir compensación alguna; lo único que le resta es la seguridad de que no se limitará el acceso a la información que se pudiera derivar del estudio y una cierta capacidad de decisión sobre la muestra, la cual tendría que ser devuelta o destruida siempre y cuando el sujeto lo solicitase.

\section{La información como particularidad de las muestras genéticas}

Toda muestra biológica es soporte de información que el médico o el científico transfor- marán en datos médicos; sin embargo, en los estudios genéticos se obtiene información que puede afectar a otras personas que no son los donantes de la muestra. Se produce la paradoja de que la autonomía de un individuo para participar en un estudio puede entrar en conflicto con la libertad de otro individuo o de toda una comunidad que no participa, ya que las consecuencias de los estudios genéticos pueden llegar a afectar a otras personas o grupos. Por esto resulta interesante plantearse el rol de la comunidad -social, de enfermos, étnica- cuando se trate de estudios, cuyas consecuencias podrían perturbar, negativa o positivamente, a una parte de ella; esto podría dar pie a un nuevo principio de la bioética: protección a la comuni$\operatorname{dad}(10)$.

A mi entender, al enfrentar el reto de la muestra biológica en los estudios farmacogenéticos se ha de asumir una doble relación. $\mathrm{La}$ muestra biológica tiene un vínculo con el sujeto, el que tendría que conocer y aceptar la finalidad y las probables consecuencias de la investigación: tendría que existir un consentimiento informado (CI) procesal. Pero, al tratarse de información genética, forma parte de una realidad más amplia (grupo familiar, poblacional, gente que padece las mismas mutaciones, por ejemplo). Sería necesario, entonces, un acuerdo o un reconocimiento por parte del grupo, comunidad o Estado para aceptar la investigación.

Como enuncia la declaración de la UNESCO sobre el genoma y los derechos humanos en su primer artículo: "El genoma humano es la base de la unidad fundamental de todos los miembros de la familia humana y del reconocimiento de su dignidad y diversidad intrínseca. En sentido simbólico el genoma humano es patrimonio de la humanidad". Pero resulta que es el individuo quien autoriza la investigación genética sobre sus muestras, aun- 
que su material genético no es de su propiedad, puesto que sus hermanos, hijos, padres, primos, poseen material genético común. Lo cual sitúa la discusión en un plano de intereses contrapuestos: el ejercicio de la autonomía de los individuos y el respeto a las sociedades o grupos étnicos. Este conflicto de intereses no puede ser abordado en el CI, siendo necesario buscar otros espacios donde dilucidar estas problemáticas, y uno de ellos podría ser dentro de los comités de ética de la investigación científica (CEIC).

\section{Límites del CI en los estudios farmacogenéticos: respeto a la autonomía individual}

El CI en investigaciones científicas, ya sean terapéuticas o no terapéuticas, presenta problemas de mucha mayor envergadura que en el caso de la clínica habitual. Los médicos clínicos han ido incorporando el CI como medida ética o como medida de protección jurídica; pero, en el caso de las investigaciones donde participan sujetos humanos, el CI se convirtió en una imposición social, como quedó en evidencia en las conclusiones del Código de Nuremberg: "El consentimiento del sujeto de experimentación es absolutamente esencial [....] el sujeto debe tener suficiente comprensión y conocimiento que le permitan ejercitar su poder de elección"'

Lo que parece evidente es que el CI tiene, principalmente, un sentido ético y que sus límites deben ser fijados o analizados por un CEIC. El consentimiento informado se establece durante el proceso dialógico, cuando el investigador participante acepta tomar parte en una investigación biomédica, epidemiológica o farmacogenética, entre muchas.

El procedimiento del CI tiene como ámbito delimitado el de la investigación; tiene como

Código de Nuremberg. objetivo informar al sujeto sobre cómo se realizará la intervención, qué riesgos corre y qué beneficios personales o sociales se pueden derivar de ésta $(11)^{8}$. Si el equipo investigador o el equipo médico pretenden utilizar las muestras para algo diferente de lo que el participante conoce, el CI no es válido y no se puede desarrollar un CI que incluya todo, como pretenden algunos autores(12). Un consentimiento puede llamarse informado sólo cuando el participante conoce para qué quiere el investigador las muestras. Si el investigador no lo sabe, se tendría que elaborar un documento en el cual el participante o el paciente autorizara al investigador para que hiciese lo que quisiera con la muestra, lo cual, a mi juicio, no sería correcto. Si se pretende que la muestra sea utilizada para cualquier fin tendría que ser anónima (disociada) ${ }^{9}$ y convertida en una muestra de acceso público, ya que nadie puede apropiarse de una información comunitaria (en un sentido figurado, el patrimonio genético es de la humanidad).

\section{El benefit sharing (reparto de beneficio): intervención de la comunidad}

El reparto de beneficios en la donación de muestras humanas es un punto controversial. Parece una buena respuesta a algunas de las inequidades que el desarrollo de la farmacogenética puede producir. Por esta razón, considero que es interesante hacer un correlato con la historia del acceso al germoplasma vegetal. En 1983 la FAO aprobó el compromiso internacional sobre recursos filogenéticos, en el cual se establecía que los recursos genéticos eran patrimonio de la humanidad y, por lo tanto, su acceso no debería estar restringido (posición similar a la de la UNESCO respecto del mate-

Declaración de Helsinki 2000. [Sitio en Internet] Disponible en http://www.wma.net/e/policy/b3.htm

9 La declaración internacional sobre los datos genéticos humanos utiliza la expresión "disociar" para hablar de la separación entre sujeto e información genética. 
rial genético humano). Esta perspectiva provocó una gran movilidad de germoplasma que trajo consigo importantes avances en la investigación y desarrollo de nuevas variedades. Casualmente, las empresas o instituciones que desarrollaban estas nuevas variedades y las iban patentando estaban situadas en los países más industrializados, lo que provocaba que los países que estaban proveyendo de germoplasma no participasen de los beneficios económicos que de allí se obtenían. Frente al reto de protección de la diversidad y a la necesidad de aprovechamiento de los recursos biológicos, el Convenio Sobre Diversidad Biológica ${ }^{10}$ modificó esta situación al considerar que los Estados particulares poseían derecho soberano sobre la biodiversidad, entendiendo que ésta es un patrimonio del Estado, como lo son los yacimientos mineros y el petróleo, entre otros.

El germoplasma pasó de ser propiedad de la humanidad a ser propiedad de los Estados y de las comunidades. El problema de fondo de la apropiación fue, aparentemente, solucionado con los acuerdos de reparto de beneficios; finalmente, el último documento asegura el acceso al germoplasma de ciertas variedades fundamentales para la alimentación, ya que éstas corrían el riesgo de ser privatizadas y regulado su acceso al pago de royalties.

En la actualidad pareciera que el material genético humano es patrimonio de la humanidad, pero que se deben acordar repartos de beneficios para suavizar asperezas. Sin embargo, el problema es mucho más profundo. La aceptación del reparto de beneficios es la rémora que se está pagando para la privatización del conocimiento. En la actualidad todos los acuerdos comerciales internacionales van en la di-

Programa de las Naciones Unidas para el Medio Ambiente. Convenio sobre la Biodiversidad Biológica. [Sitio en Internet] Disponible en http://www.biodiv.org/convention/ articles.asp?lg=1 rección de protección del conocimiento (acuerdos OMC, tripps plus). De modo que el problema no es el reparto de beneficios, sino la accesibilidad a los datos obtenidos: que haya acceso al conocimiento sin violar la confidencialidad y dignidad de los sujetos cuando las muestras han sido dadas sin ningún interés económico.

Actualmente, existen algunos documentos internacionales que pretenden sentar algunas normas para que el desarrollo de las bases de datos genéticas y los bancos de muestras no sea incontrolado, caótico e irrespetuoso de las libertades personales, tales como la Declaración Internacional sobre los Datos Genéticos Humanos, de las Naciones Unidas; la Convención para la Protección de los Derechos Humanos y la Dignidad del Ser Humano con Respecto a las Aplicaciones de la Biología y la Medicina, de la Unión Europea, además de otras declaraciones de la UNESCO; pero el desarrollo de la genética y la capacidad de manipular grandes bases de datos está superando las previsiones.

Los bancos de datos genéticos están creciendo de modo asimétrico. Pertenecen, principalmente, a las empresas farmacéuticas y al NIH, en EE.UU., quienes llegan a poseer más de un millón de muestras de la gran mayoría de grupos étnicos del mundo. Si, además, ello se une al hecho de que las patentes biotecnológicas relacionadas con la salud humana son generadas en los países industrializados, la asimetría se agudiza. Resulta curioso que tanta desigualdad real sea enmascarada por numerosas declaraciones internacionales de buenas intenciones. Si nos remitimos al espíritu de las Pautas CIOMS, o a la declaración europea sobre genómica, se afirma que se desarrollarán y fortalecerán las capacidades de los países en desarrollo para que puedan realizar investigaciones sobre biología y genética humana, de otra manera la utilización de los ciudadanos podría 
considerarse discriminatoria. Obsérvese, entonces, la paradoja argumentativa: hay que fomentar la investigación farmacogenética y la circulación de las muestras y datos en los países en desarrollo; pero, por otro lado, se utilizará esta información genética para fines médico-comerciales. La información que se obtenga, con el objetivo de mejorar la salud de los ciudadanos, será protegida mediante el resguardo intelectual; pero se retrasará la publicación de los resultados y su utilización estará sujeta a pago de royalties. Y estas patentes, curiosamente, estarán en manos de corporaciones transnacionales, cuyas sedes no se encuentran ni en Bolivia, Perú, Argentina, Mongolia o Senegal.

Una posible forma de contrarrestar esta asimetría sería exigiendo que los análisis genéticos y las muestras quedaran en los centros hospitalarios o en alguna entidad del ministerio de salud de cada país, para facilitar el acceso público restringido a los datos, siempre que se investigase en enfermedades autorizadas por el participante. Así, cada estudio que se realizase iría dejando cierto banco de muestras genéticas en los países de origen. Esta opción está inspirada en el análisis de algunos CI de estudios realizados en Estados Unidos que ofrecen al participante dejar una muestra suya en manos de algún banco de muestras del Estado o de un hospital público; de esta manera, se obtiene mayor accesibilidad a la información dificultando su retención, y se protege la fuente primera de una posible apropiación indebida. Aunque, con la tendencia privatizadora de muchos países de la región americana, no sé si esto representaría una salvaguarda suficiente.

El gran problema reside en que la accesibilidad sin protección de la información genética puede llevar a su apropiación indebida por parte de empresas y centros de investigación universitarios con el beneplácito de las oficinas de patentes. Sería interesante buscar una figura jurídica como el copyleft, que impidiese la apropiación y posterior protección de la información por parte de una empresa. Esta figura legal estipula que está permitida la reproducción total o parcial de estos datos y su difusión, siempre y cuando sea para uso personal de los investigadores y no con fines comerciales ${ }^{11}$. Considero que la unión y formalización de la figura de la donación con la de protección mediante un sistema de copyleft, en los casos en que no exista otra medida de protección, pueden crear los primeros espacios para replicar a la máxima de la necesidad de protección intelectual mediante el sistema de patentes.

\section{Conclusión}

Posiblemente sea necesario dejar de escribir declaraciones internacionales y convertir en realidad las ya ratificadas, presentadas o aprobadas. Es imperioso que permanezca un remanente científico-tecnológico en todos los países de la región en cuyas poblaciones se están realizando estudios farmacogenéticos. Además, deben sentarse las bases para que esta información genere espacios de investigación en estos países y no termine siendo apropiada por grandes corporaciones. Pero el compromiso para evitar la apropiación debe ser asumido por los centros de investigación y los investigadores de países como Estados Unidos, el Reino Unido, Japón, Alemania, Francia, Canadá, entre otros, ya que la investigación en Latinoamérica, a excepción de Brasil y México, es marginal.

Finalmente, existe un importante interés por parte de la industria farmacéutica por generar una muy buena percepción de la farmacogenética antes de desarrollar los productos, lo cual pareciera ser una estrategia de penetración para limitar la reflexión sobre ciertos asuntos. Es curioso que la mayor parte de las publicaciones sobre aspectos

11 GNU Operating System-Free Software Foundation. ¿Qué es Copyleft? [Sitio en Internet] Disponible en http://www.gnu.org/ copyleft/copyleft.es.html 
éticos y sociales de la farmacogenómica y farmacogenética procedan de investigadores que realizan trabajos parcial o totalmente financiados por la industria farmacéutica, como GlaxoSmithKline (13). Sería muy importante meditar sobre el proceso de protección de la información genética que ya se ha producido y asumir que, en el marco actual, la información ha de ser protegida contra apropiación indebida. Además, los países de Latinoamérica tendrán que estudiar y regular, estrictamente, el movimiento de muestras biológicas y datos genéticos, sin recibir ningún tipo de compensaciones más allá de las del futuro beneficio terapéutico, el cual queda muy lejos de las posibles aspiraciones de los sistemas públicos de salud de la región. Otro elemento posiblemente conflictivo puede ser la existencia de diferentes normativas de acceso a bases de datos y confi- dencialidad: si la muestra sale del país es difícil realizar acciones para proteger que la confidencialidad de la información no sea violada.

Se debe efectuar una tarea en cinco ámbitos: primero, cumplimiento estricto de las normativas internacionales; segundo, asunción de que la muestra biológica es parte del paciente; tercero, supervisión rigurosa de las patentes biotecnológicas en las que intervengan material o datos genéticos humanos; cuarto, exigencia de contraprestaciones a los patrocinadores de investigaciones para que quede en el país un remanente tecnológico que pueda ser utilizado en otras situaciones; y, quinto, creación de un sistema público de bases de datos genéticos que esté protegido, posiblemente, por un sistema parecido al copyleft en informática.

\section{Agradecimientos}

Este trabajo fue posible gracias a una beca Fogarty NIH Research Grant \#D43 TW 06056, que me permitió realizar estudios de postítulo en el Programa Internacional de Investigación Biomédica y Psicosocial en Santiago de Chile.

\section{Referencias}

1. The cost of adverse drug reactions (editorial). Adverse Drug Reaction Toxicology Review 1997; 16: 75-8.

2. Lazarou J, Pomeranz BH, Corey PN. Incidence of adverse drug reactions in hospitalized patients. A meta analysis of prospective study. JAMA 1998; 279:1200-5.

3. Roses AD. Pharmacogenetics and the practice of medicine. Nature 2000; 405: 857-65.

4. Roland C, Smith G, Smith R. Science, medicine and the future. British Medical Journal 2000; 320: 987-90.

5. Jiménez NP. Los derechos de los pacientes sobre su muestra biológica. Distintas opiniones jurisprudenciales. Revista de Derecho y Genoma Humano 2003; 19: 207-28.

6. Godelier M. El enigma del Don. Barcelona: Paidós; 1998: 286.

7. ¿Las muestras biológicas terreno de nadie? (editorial) Revista de Derecho y Genoma Humano 2002; 17: 1719 .

8. Consejo de Europa. Convenio para la protección de los Derechos Humanos y la dignidad del ser humano con respecto a las aplicaciones de la biología y la medicina. Oviedo: Consejo de Europa; 1997. 
El Reto de la Muestra Biológica en los Estudios Farmacogenéticos - A. Bota

9. Nicolás Jiménez P. Los derechos del paciente sobre su muestra biológica: distintas opiniones jurisprudenciales. Revista de Derecho y Genoma Humano 2003; 19: 207-27.

10. Rothstein MA, Epps PG. Ethical and legal implications of pharmacogenomics. Nature Reviewed Genetics 2001; 2(3): 229.

11. Consejo de Organizaciones Internacionales de las Ciencias Médicas. Pautas Éticas Internacionales para la Investigación Biomédica en Seres Humanos CIOMS 2002. Santiago de Chile: Programa Regional de Bioética OPS/OMS; 2003.

12. Romeo-Casabona CM. Los genes y sus leyes. El derecho ante el genoma humano. Bilbao-Granada: Editorial Comares; 2002: 171.

13. Bellver Capella V. Ética, política y derechos en farmacogenómica. Revista de Derecho y Genoma Humano 2002; 17: 47. 